\title{
Hypoxia-preconditioned mesenchymal stem cells attenuate peritoneal adhesion through TGF- $\beta$ inhibition
}

\author{
Setyo Trisnadi ${ }^{*}$, Adi Muradi Muhar ${ }^{* *}$, Agung Putra ${ }^{*, * * *,}$, and Azizah Retno Kustiyah ${ }^{\dagger, *}$
}

ABSTRACT

\section{BACKGROUND}

Peritoneal adhesions (PAs) are generally described as fibrous bands between intra-abdominal organs following an abdominal surgical operation. The definitive treatments of PAs are currently ineffective yet. Hypoxiamesenchymal stem cells (H-MSCs) have a higher capability to survive at the site of injury than normoxia-MSCs (N-MSCs) to repair injured tissue without fibrosis. This study aimed to analyze the effect of H-MSCs in controlling formation of PAs by reducing TGF- $\beta$ level in a rat model.

\section{METHODS}

A study of post-test only control group design was conducted, involving eighteen PA rat models weighing $250 \pm 25 \mathrm{~g}$ that were randomly assigned into 3 groups, comprising control group (C), and groups $\mathrm{T} 1$ and $\mathrm{T} 2$ receiving H-MSC treatment at doses of $3 \times 10^{6}$ and $1.5 \times 10^{6}$, respectively. To induce $\mathrm{H}-\mathrm{MSC}$, MSCs were incubated in hypoxic conditions at $5 \% \mathrm{O}_{2}$ and $37^{\circ} \mathrm{C}$ for 24 hours. Expression level of TGF- $\beta$ was analyzed by enzyme-linked immunosorbent assay (ELISA) at $450 \mathrm{~nm}$ and adhesion formation was described macroscopically. The Kruskal-Wallis variance analysis was used to analyze significant differences among the groups.

\section{RESULTS}

The results of this study showed that H-MSCs in group T1 inhibited TGF$\beta$ expression significantly on day $8(\mathrm{p}<0.001)$ and day $14(\mathrm{p}<0.05)$. Moreover, there was almost no adhesion apparent following H-MSC administration in group T1.

\section{CONCLUSIONS}

Based on this study, we conclude that H-MSCs may attenuate PA formation following inhibition of TGF- $\beta$ expression in the PA rat model.

Keywords: Peritoneal adhesions, hypoxia, H-MSCs, TGF- $\beta$, rat
${ }^{*}$ Department of Postgraduate

Biomedical Science, Medical Faculty, Sultan Agung Islamic University (UNISSULA), Semarang, Central Java, Indonesia

${ }^{* *}$ Department of Surgery, Medical

Faculty, Universitas Sumatera Utara

(USU), Medan, Indonesia

${ }^{* * *}$ Department of Pathological

Anatomy, Medical Faculty, Sultan Agung Islamic University

(UNISSULA), Semarang, Central

Java, Indonesia

Stem Cell And Cancer Research (SCCR), Medical Faculty, Universitas Islam Sultan Agung (Unissula), Semarang, Central Java, Indonesia tDepartment of Pediatrics, Medical Faculty, Universitas Islam Sultan Agung (Unissula), Semarang, Central Java, Indonesia

Correspondence :

Agung Putra, MD

Chairman of Stem Cell and Cancer Research (SCCR) Laboratory, Faculty of Medicine, Sultan Agung Islamic University, Semarang Jl. Raya Kaligawe KM. 4 Semarang, Central Java 50112

Phone +628164251646 ,

Fax. 0246594366

Email: dr.agungptr@gmail.com ORCID ID: 0000-0003-4261-9437

Date of first submission, October 10, 2019

Date of final revised submission, July 8 , 2020

Date of acceptance, July 9, 2020

This open access article is distributed under a Creative Commons AttributionNon Commercial-Share Alike 4.0 International License 


\section{INTRODUCTION}

Peritoneal adhesions (PAs) are fibrous bands between two or more intra-abdominal organs or between these organs and the inner abdominal wall, due to secondarily prolonged inflammation of an abdominal surgical operation. ${ }^{(1)}$ The occurrence of PAs approaches $63-97 \%$ and approximately one-third of such cases are readmitted due to complications. PAs may cause complications such as abdominal or pelvic pain, small bowel obstructions, and infertility. ${ }^{(2)}$ Although the definitive treatment of PAs such as laparoscopic adhesiolysis and/or laparotomy adhesiolysis has the benefit of reducing the PAs, those treatments have the potential to induce several complications such as small bowel obstructions and the risk of PA recurrence. ${ }^{(3-5)}$ Therefore, more effective and safer treatment of PAs is needed.

Mesenchymal stem cells (MSCs) are a population of pleiotropic cells with self-renewing capacity that have the ability to differentiate into various canonical mesenchymal cells, namely adipocytes, chondrocytes, and osteocytes. ${ }^{(6)}$ MSCs express a number of markers, such as CD29, CD44, CD73, CD90, CD105, CD166, but are lacking in CD14, CD34, CD45, or CD11b, CD79a or CD19, and HLA class II expression. ${ }^{(7)}$ A recent study reported that hypoxia offers benefits to MSCs for increasing their capability of self-renewal, proliferation, and survival gene modulation. ${ }^{(8)}$ Hypoxia-mesenchymal stem cells (H-MSCs) can mimic a physiological niche in the bone marrow that potentially offers the benefits of a wound healing process. This is in line with a previous study reporting that one of the therapeutic failures of MSC administration was poor engraftment capacity and low cell survivability during the transplantation process at the hypoxia injury site. ${ }^{(9)}$ This fact showed that the competence of MSCs to survive under hypoxic conditions in preventing PA formation was crucial to be explored. ${ }^{(10)}$ Furthermore, HMSCs are more robust cells in controlling inflammation than N-MSCs through increasing
IL-10 production to tightly compete with TGF- $\beta$ for fibroblast activation. ${ }^{(11)}$

The pathogenesis of PAs involves several inflammatory factors to stimulate the prolonged release of TGF- $\beta$ leading to the activation of fibroblasts and adhesion formation. ${ }^{(12)}$ A previous study revealed that MSCs cultured in hypoxia exhibit higher rates of proliferation and better retain their stem cell properties, including PAs. ${ }^{(13)}$ Our previous study showed that H-MSCs can survive in injured tissues and have the capacity to reduce PA formation and suppress inflammatory conditions by releasing IL-10 as a pleiotropic anti-inflammatory cytokine. ${ }^{(14)}$ However, the role of H-MSCs in decreasing TGF- $\beta$ as the main cytokine of the main fibrosis mechanism in PA formation remains unclear. Therefore, to decrease TGF- $\beta$ through H-MSC administration for inhibiting PA formation was crucial to be investigated. In this study, we aimed to analyze the effect of H-MSCs in controlling PA formation by reducing TGF- $\beta$ levels.

\section{METHODS}

\section{Research design}

This study of post-test only control group design was carried out in the Stem Cell and Cancer Research Laboratory, Faculty of Medicine, Universitas Islam Sultan Agung (Unissula), Semarang from August-October 2018.

\section{PA animal model}

The sample size was calculated according to the Federer formula. ${ }^{(15)}$ This study used eighteen Wistar albino rats which were randomly divided into 3 groups, consisting of the control group, the high dose group (T1) and the low dose group (T2) ( $\mathrm{n}=6$ rats per group) with $10 \%$ estimated drop-out rate. The Wistar albino rats weighing between 250 and $300 \mathrm{~g}$ were purchased from the animal holding unit, Faculty of Veterinary Medicine, Gadjah Mada University. Rats were acclimatized and housed in $12 \mathrm{~h}$ light-dark cycle standard cages at $24^{\circ} \mathrm{C}$ with food and water ad libitum. After fasting for $12 \mathrm{~h}$, rats were 
anesthetized by intraperitoneal administration of ketamine and xylazine (90 and $10 \mathrm{mg}$ per $\mathrm{kg}$ body weight; respectively). The surgical procedure was performed as described previously. ${ }^{(14)}$ The operations were performed under aseptic conditions and took less than 20 minutes for each rat to minimize room air tissue dying effect. The musculo- peritoneal layer was incised and opened over a length of $3 \mathrm{~cm}$ at the linea alba after cutaneous ventral midline incision. In order to induce PAs, the standardized surgical injuries were applied to one side of the terminal ileum ( $3 \mathrm{~cm}$ from the cecum) at a size of $0.5 \times 0.5 \mathrm{~cm}$ on the right sidewall of the ileum by brushing with a cytobrush (Gynobrush, Langenbrink, Emmendingen, Germany) until punctuate red spots were observable as visual indicator of ileum trauma. Following the intervention, the abdominal incision was closed with 3-0 polyglactin suture and the rats were reared in battery cages for 14 days.

\section{MSC isolation culture and H-MSC induction}

Mesenchymal stem cells were isolated from the umbilical cord (UC) obtained from pregnant single Wistar albino rats and expanded as described previously. ${ }^{(8)}$ Briefly, UCs were chopped into smaller pieces and transferred into a T25 culture flask (Corning, Tewksbury, MA, USA) containing DMEM (Gibco ${ }^{\text {TM }}$ Invitrogen, NY, USA) which was supplemented with $10 \%$ FBS (Gibco ${ }^{\mathrm{TM}}$ Invitrogen, NY, USA), 1\% penicillin $(100 \mathrm{U} / \mathrm{mL})$ and $0.25 \%$ streptomycin $(100 \mu \mathrm{g} / \mathrm{mL})\left(\mathrm{Gibco}^{\mathrm{TM}}\right.$ Invitrogen, NY, USA) and incubated at $37^{\circ} \mathrm{C}$ in $5 \% \mathrm{CO}_{2}$ and e" $95 \%$ humidity. The medium was replaced every 3 days and the cells harvested after reaching $80 \%$ confluence (14 days). The 4-6th passage MSClike cells were employed for the experiments.

To induce H-MSCs, MSCs derived from the 4th passage were incubated under 5\% O2 condition in a hypoxia incubation chamber (STEMCELL Technologies, Biopolis, Singapore) for $24 \mathrm{~h}$ at $37^{\circ} \mathrm{C}$ and $5 \% \mathrm{CO} 2$, then collected for the following experiment.

\section{H-MSC characterization}

Hypoxic-mesenchymal stem cell surface markers at the 4-6th passage were analyzed by flow cytometry analysis according to company protocols. Briefly, the cells were subsequently incubated in the darkroom with allophycocyanin (APC) mouse anti-human CD73, fluorescein isothiocyanate (FITC) mouse anti-human CD90, perCP-Cy5.5.1 mouse anti-human CD105, and phycoerythrin (PE) mouse anti-human Lin negative (CD45/CD34/CD11b/CD19/HLA-DR) antibodies. H-MSC cells were stained with MSC specific antibody for 30 minutes at $4^{\circ} \mathrm{C}$, then examined and analyzed with a BD Accuri C6 Plus flow cytometer (BD Biosciences, San Jose, CA, USA).

\section{H-MSC osteogenic differentiation assay}

The H-MSCs were cultured on 24-well plates $\left(1.5 \times 10^{4}\right.$ cells/well density) with standard medium containing DMEM (Sigma-Aldrich, Louis St, MO), supplemented with $10 \%$ FBS (Gibco ${ }^{\text {TM }}$ Invitrogen, NY, USA), $1 \%$ penicillin $(100 \mathrm{U} / \mathrm{mL})$ and $0.25 \%$ streptomycin $(100 \mu \mathrm{g} / \mathrm{mL})\left(\mathrm{Gibco}^{\mathrm{TM}}\right.$ Invitrogen, NY, USA) at $37^{\circ} \mathrm{C}, 5 \% \mathrm{CO} 2$, and e" $95 \%$ humidity. After reaching $95 \%$ confluence, the standard medium was aspirated and replaced with osteogenic differentiation medium containing Human MesenCult ${ }^{\mathrm{TM}}$ Osteogenic Differentiation Basal Medium (Stem Cell Technologies, Singapore), augmented with $20 \%$ Human MesenCult ${ }^{\mathrm{TM}}$ Osteogenic Differentiation 5X Supplement (Stem Cell Technologies, Singapore) and 1\% L-Glutamine (Gibco ${ }^{\mathrm{TM}}$ Invitrogen, NY, USA). The differentiation medium was replaced every 3 days. The bone matrix was formed after 15 days and was visualized by $2 \%$ Alizarin red staining.

\section{H-MSC administration}

After the surgical procedure of PA induction, the rats were treated once with $3 \times 10^{6}$ cells for the $\mathrm{T} 1$ group and $1.5 \times 10^{6}$ cells for the $\mathrm{T} 2$ group via submucosal injection, while the control group received the omental patch treatment. 
Table 1. Nair's macroscopic adhesion grade ${ }^{(16)}$

\begin{tabular}{ll}
\hline Grade 0 & No adhesion \\
Grade 1 & Only one adhesion band between abrasion site and abdominal wall \\
Grade 2 & Two adhesion bands between abrasion site and abdominal wall \\
Grade 3 & More than two adhesion bands between abrasion site and abdominal wall \\
Grade 4 & Adhesion of all viscera to the abdominal wall \\
\hline
\end{tabular}

\section{ELISA assay}

At days 8 and 14 post-PA surgical procedure, ELISA was used to measure the level of TGF- $\beta$ released in rat peripheral blood in the treatment and control groups. The analysis was done according to the manufacturer's instructions (Fine Test, Wuhan, China) using a standard curve and was performed in five replications. The colorimetric absorbance wavelength used was $450 \mathrm{~nm}$.

\section{Macroscopic analysis}

The induced PA rat animal models were euthanized using $\mathrm{CO} 2$ inhalation on the $14^{\text {th }}$ day after treatment. The adhesion formation was observed, and categorized using Nair's Adhesion Grade (Table 1). ${ }^{(16)}$

(a)
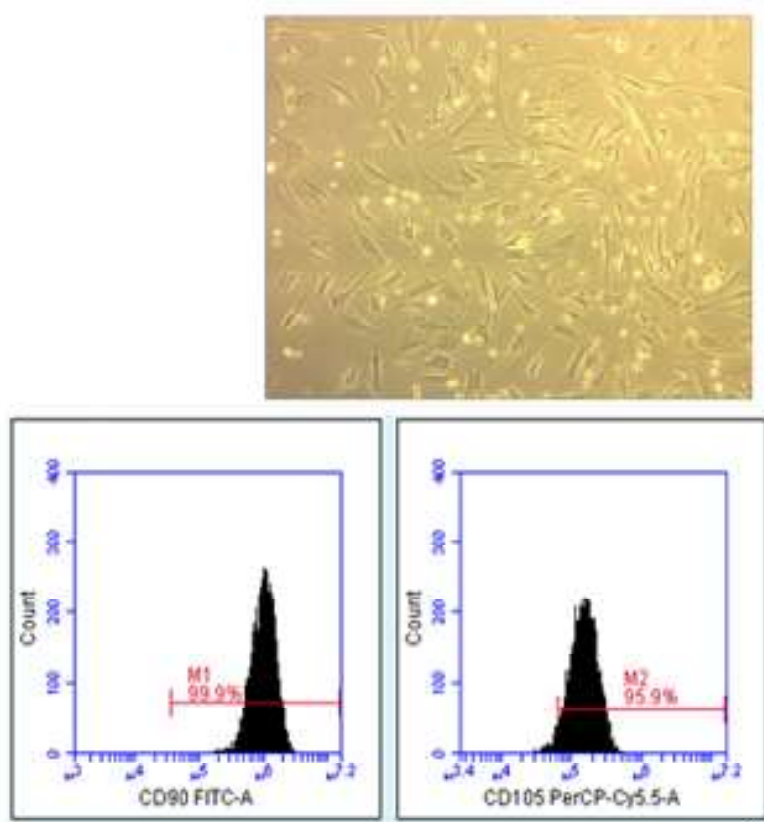

\section{Statistical analysis}

The statistical analysis was performed using the SPSS ver. 23 (SPSS Inc., Chicago, IL, USA). Descriptive data were expressed as mean \pm standard error. For intergroup analysis, the Kruskal-Wallis variance analysis was used to analyze significant differences among the groups. And Mann Whitney test to compare between groups. A p-value of less than 0.05 was considered statistically significant.

\section{Ethical clearance}

The study was approved by the Health Research Ethical Committee, Medical Faculty, Universitas Sumatera Utara, Medan, Indonesia, under No. 541/TGL/KEPK FK USU-RSUP $\mathrm{HAM} / 2019$.

(b)
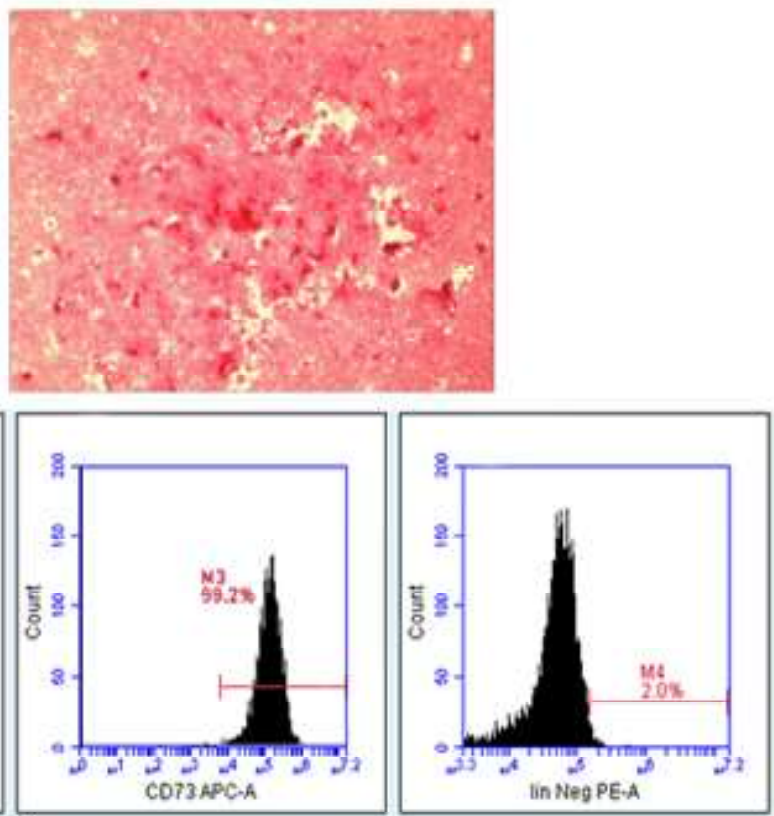

(c)

Figure 1. (a) H-MSCs from the in-vitro culture showing spindle shape and fibroblast-like characteristics (10x magnification) ; (b) Osteogenic differentiation analysis using alizarin red staining showing calcium deposition marked by red color ; (c) Flow cytometry analysis of H-MSCs confirmed that H-MSCs expressed high levels of 

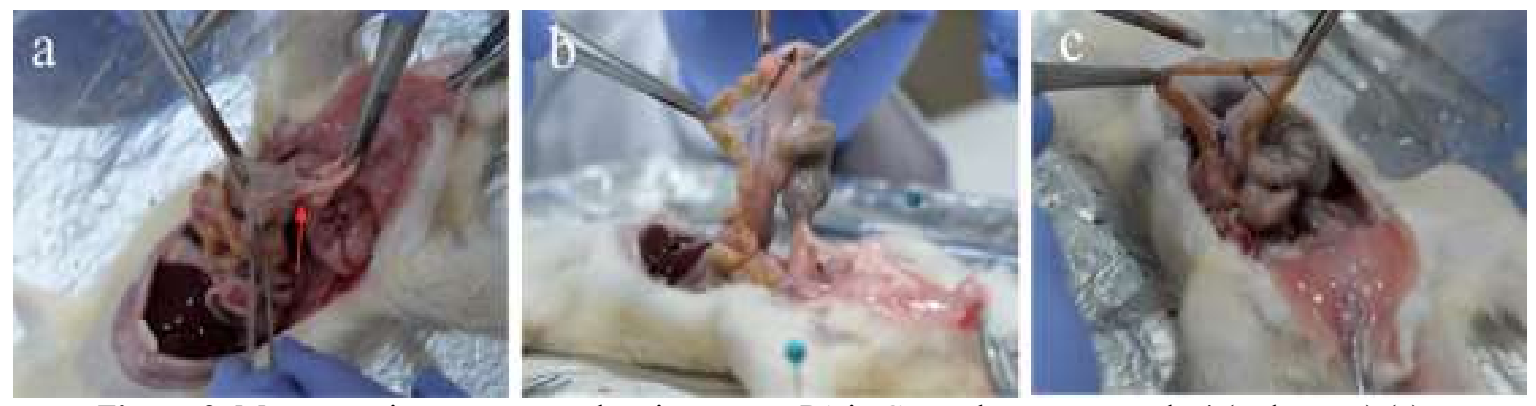

Figure 2. Macroscopic appearance showing severe PA in Control group at grade 4 (red arrow) (a).

Treatment groups showing fewer adhesions in the T2 group (b); and almost no adhesions in the $\mathrm{T} 2$ group (black arrow) (c)

\section{RESULTS}

\section{H-MSC characterization and differentiation}

The H-MSCs that were incubated from the $4^{\text {th }}$ passage at $80 \%$ confluence under hypoxic conditions $\left(5 \% \mathrm{O}_{2}\right)$ showed denser fibroblast and spindle-like shape characteristics (Figure 1a). After undergoing the osteogenic differentiation assay the H-MSCs showed calcium deposition under 2\% Alizarin red staining (Figure 1b). The flow cytometry analysis confirmed that H-MSCs expressed high levels of CD90 (99.9\%), CD105 (95.9\%), CD73 (99.2\%) and lacked the expression of $\operatorname{Lin}^{-}(2.0 \%)$ thereby demonstrating a characteristic immunophenotype of MSCs (Figure 1c).

\section{Macroscopic assessment}

The Nair macroscopic adhesion grade was used to describe adhesion occurrence in this study. There was Grade 4 adhesion in the control group, no adhesion in group T1 (Grade 0), and less adhesion in group T2 (Grade 1) (Figure 2).

\section{TGF- $\beta$ expression analysis}

We analyzed TGF- $\beta$ levels as an inflammatory marker of the ileum tissue. TGF- $\beta$ expression was detected using ELISA assay. The results showed that the TGF- $\beta$ expression level in groups $\mathrm{T} 1$ and $\mathrm{T} 2$ were significantly lower than in the control group on both the $8^{\text {th }}$ and $14^{\text {th }}$ days $(\mathrm{p}<0.05)$ (Table 2).

\section{DISCUSSION}

PAs are commonly fibrous bands occurring after abdominal surgery that have severe complications of life quality. ${ }^{(17)}$ The pathology of peritoneal fibrinolysis reduction is thought to play a key role in PA pathogenesis. ${ }^{(18)}$ Inflammatory cytokines such as IL-17 may also promote PAs by increasing the activation of fibroblasts along with TGF- $\beta 1$ stimulation. ${ }^{(19)}$ A previous study reported the potential of MSCs to treat PA formation. ${ }^{(20)}$ However, although MSCs were able to reduce peritoneal inflammation, they were ineffective in controlling PAs. ${ }^{(21)}$ Hypoxia-MSCs have positive effects on the in vitro stemness, survival capacity, and angiogenic potential that is mediated by hypoxia-inducible factors (HIFs), such as HIF- $1 \alpha$ and HIF-2 $\alpha{ }^{(22)}$ To analyze the effect of H-MSCs in preventing PA formation, we induced abrasion in rats as the established animal model of PAs according to a previous

Table 2 . TGF- $\beta$ levels according to treatment groups at $8^{\text {th }}$ and $14^{\text {th }}$ days

\begin{tabular}{lcccc}
\hline & \multicolumn{3}{c}{ Treatment groups } & p value* \\
\cline { 2 - 4 } & T1 & T2 & C & \\
\hline TGF- $\beta$ level $(\mathrm{pg} / \mathrm{mL})$ & & & & \\
$8^{\text {th }}$ day & $492.04 \pm 53.50$ & $645.05 \pm 59.89$ & $699.68 \pm 18.75$ & $\mathrm{~T} 1=0.008 ; \mathrm{T} 2=0.008$ \\
$14^{\text {th }}$ day & $450.88 \pm 20.86$ & $539.50 \pm 43.79$ & $563.55 \pm 26.24$ & $\mathrm{~T} 1=0.008 ; \mathrm{T} 2=0.032$ \\
\hline
\end{tabular}

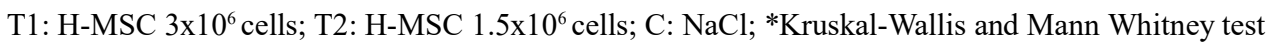


study. ${ }^{(23)}$ In this study, we transplanted the HMSCs into PA rat models directly to the ileum by submucosal injection, then analyzed the TGF- $\beta$ on day 8 and 14 .

Our study found that there was a significant decrease in TGF- $\beta$ levels in the T1 and T 2 groups on days 8 and 14. Our results indicate that there was complete wound healing in the H-MSC groups as compared with the control group. This finding was in line with our Nair macroscopic analysis in which there were PAs in the control group but no adhesion formation in the H-MSC treatment groups. A previous study reported that MSCs could attenuate peritoneal adhesion through increasing the level of TNF- $\alpha$ Stimulating Gene6 (TSG-6) to reduce the inflammatory process. ${ }^{(24)}$ This is in line with our previous study revealing that H-MSCs could increase the level of IL-10 as a major anti-inflammatory cytokine to control adhesion formation. ${ }^{(14)}$ This indicated that $\mathrm{H}$ MSCs could accelerate wound healing and attenuate PA formation through the decrease in TGF- $\beta$ levels. A recent study found that proinflammatory cytokines such as TNF- $\alpha$ and IL$1 \beta$ may stimulate TGF- $\beta$ production to induce the activation of myofibroblasts (MFs) for PA formation. ${ }^{(25)}$ A previous study also reported that H-MSCs could decrease the expression levels of various pro-inflammatory cytokines, such as TNF- $\alpha$, IL- $1 \beta$, and MIP- 2 , and promote the secretion of anti-inflammatory molecules, including IL-10 and prostaglandin $\mathrm{E}_{2}\left(\mathrm{PGE}_{2}\right)$. ${ }^{(26)}$ The IL-10 as anti-inflammatory molecules could suppress the TGF- $\beta$ level which might be attributed to the inactivation of MF that have crutial roles in adhesion formation. ${ }^{(27)}$

This study also demonstrated the dosedependent effect of H-MSCs. This was in accordance with a previous study that found a progressive increase in the number of altered cytokines at higher doses of MSCs. ${ }^{(28,29)}$ The interaction between these pro- and antiinflammatory molecules at the injury site following H-MSC administration may explain the TGF- $\beta$ lowering effect of H-MSCs. This was supported by our morphological findings, in which there were fibrous bands of PAs in the control group. These findings indicated that inflammation could be optimally controlled by high doses of H-MSCs. The fibrin matrix contained in the initial adhesion was replaced by extracellular matrix (ECM) under prolonged inflammation due to the ECM synthesis being more active than the degradation process, leading to the formation of new endothelial layers connecting to other organs. ${ }^{(30,31)}$ The activated MFs that were characterized by $\alpha$-Smooth Muscle Actin ( $\alpha$-SMA) were the main actors of these processes to produce ECM in excessive amounts due to the incompetence of IL-10 of the control group to suppress the inflammation. ${ }^{(14,21)}$

This study has a limitation, as we did not observe the expression of $\alpha$-SMA in myofibroblasts, thus we could not confirm the role of H-MSCs in reducing PA formation. In addition, the number of lymphocytes as a hallmark of prolonged inflammation in the wound area was not investigated, which is the other limitation of this study. This study provides new insights on the benefits of H-MSC administration for inhibiting PA formation post abdominal surgical operation. Further studies are warranted to confirm the effect of H-MSCs in inhibiting MF activity that might provide important evidence for their potential clinical applications.

\section{CONCLUSIONS}

In conclusion, our data demonstrate that $\mathrm{H}$ MSCs attenuate PA formation through suppressing TGF- $\beta$ expression.

\section{REFERENCES}

1. Tabibian N, Swehli E, Boyd A, Umbreen A, Tabibian JH. Abdominal adhesions: a practical review of an often overlooked entity. Ann Med Surg (Lond) 2017;15:9-13. doi: 10.1016/j.amsu. 2017.01.021.

2. Arung W, Meurisse M, Detry O. Pathophysiology and prevention of postoperative peritoneal adhesions. World J Gastroenterol 2011;17:454553. doi: 10.3748/wjg.v17.i41.4545. 
3. Wang G, Wu K, Li W, et al. Cross talk between IL 17 and TGF $\beta$. Wound Repair Regen 2014;22: 6319. doi: 10.1111/wrr.12203.

4. Rocca A, Aprea G, Surfaro G, et al. Prevention and treatment of peritoneal adhesions in patients affected by vascular diseases following surgery: a review of the literature. Open Med (Wars) 2016; 11:106-14. doi: 10.1515/med-2016-0021.

5. Yao S, Tanaka E, Matsui Y, et al. Does laparoscopic adhesiolysis decrease the risk of recurrent symptoms in small bowel obstruction? A propensity score-matched analysis. Surg Endosc 2017;31:5348. https://doi.org/10.1007/ s00464-017-5615-9.

6. Glenn JD, Whartenby KA. Mesenchymal stem cells: emerging. mechanisms of immunomodulation and therapy. World J Stem Cells 2014;6:526-39. doi: 10.4252/wjsc.v6.i5.526.

7. Maleki M, Ghanbarvand F, Behvarz MR, Ejtemaei M, Ghadirkhomi E. Comparison of mesenchymal stem cell markers in multiple human adult stem cells. Int J Stem Cells 2014;7:118-26. http:// dx.doi.org/10.15283/ijsc.2014.7.2.118.

8. Raoufi MF, Tajik P, Dehghan MM, Eini F, Barin A. Isolation and differentiation of mesenchymal stem cells from bovine umbilical cord blood. Reprod Domest Anim 2011;46:95-9. doi: 10.1111/j.14390531.2010.01594.x.

9. Yustianingsih V, Sumarawati T, Putra A. Hypoxia enhances self-renewal properties and markers of mesenchymal stem cells. Univ Med 2019;38:16471. doi: 10.18051/UnivMed.2019.v38.156-163.

10. Salazar Noratto GE, Luo G, Denoeud C, et al. Concise review: understanding and leveraging cell metabolism to enhance mesenchymal stem cell transplantation survival in tissue engineering and regenerative medicine applications. Stem Cells 2020;38:22-33. doi: 10.1002/stem.3079.

11. Lotfinia M, Lak S, Mohammadi Ghahhari N, et al. Hypoxia pre-conditioned embryonic mesenchymal stem cell secretome reduces IL-10 production by peripheral blood mononuclear cells. Iran Biomed J 2017;21:24-31. doi: 10.6091/.21.1.24.

12. Caja L, Dituri F, Mancarella S, et al. TGF- $\beta$ and the tissue micro environment: relevance in fibrosis and cancer. Int J Mol Sci 2018;19:1294. https://doi.org/10.3390/ijms 19051294PMid: 29701666.

13. Bobyleva PI, Andreeva ER, Gornostaeva AN, Buravkova LB. Tissue-related hypoxia attenuates proinflammatory effects of allogeneic PBMCs on adipose-derived stromal cells in vitro. Stem Cells Int 2016;2016:4726267. doi: 10.1155/2016/4726267.

14. Muhar AM, Putra A, Warli SM, Munir D. Hypoxiamesenchymal stem cells inhibit intra-peritoneal adhesions formation by upregulation of the IL-
10 expression. Maced J Med Sci 2019;7:3937-43. doi: 10.3889/oamjms.2019.713.

15. Charan J, Kantharia ND. How to calculate sample size in animal studies?. J Pharmacol Pharmacother 2013;4:303-6. doi:10.4103/0976-500X.119726.

16. Karaca G, Pehlivanli F, Aydin O, et al. The effect of mesenchymal stem cell use on intraabdominal adhesions in a rat model. Ann Surg Treat Res 2018;94:57-62. https://doi.org/10.4174/astr.2018. 94.2.57.

17. Moris D, Chakedis J, Rahnemai-Azar AA, et al. Postoperative abdominal adhesions: clinical significance and advances in prevention and management. J Gastrointest Surg 2017;21:171322. https://doi.org/10.1007/s11605-017-3488-9.

18. Wei G, Chen X, Wang $G$, et al. Inhibition of cyclooxygenase-2 prevents intra-abdominal adhesions by decreasing activity of peritoneal fibroblasts. Drug Des Devel Ther 2015;9:308398. doi: 10.2147/DDDT.S80221.

19. Wang G, Wu K, Li W, et al. Cross talk between IL 17 and TGF $\beta$. Wound Repair Regen 2014;22: 6319. doi: 10.1111/wrr.12203.

20. Yang B, Gong C, Qian Z, et al. Prevention of postsurgical abdominal adhesions by a novel biodegradable thermosensitive PECE hydrogel. BMC Biotechnol 2010;10:65. doi:10.1186/14726750-10-65.

21. Wang N, Shao Y, Mei Y, et al. Novel mechanism for mesenchymal stem cells in attenuating peritoneal adhesion: accumulating in the lung and secreting tumor necrosis factor $\alpha$-stimulating gene-6. Stem Cell Res Ther 2012;3:51. doi: 10.1186/ scrt142.

22. Lv B, Li F, Fang J, et al. Hypoxia inducible factor $1 \alpha$ promotes survival of mesenchymal stem cells under hypoxia. Am J Transl Res 2017;9:1521-9.

23. Kraemer B, Wallwiener C, Rajab TK, Brochhausen C, Wallwiener M, Rothmund R. Standardised models for inducing experimental peritoneal adhesions in female rats. Biomed Res Int 2014; 4350-56. doi: 10.1155/2014/435056.

24. Wang N, Li Q, Zhang L, et al. Mesenchymal stem cells attenuate peritoneal injury through secretion of TSG-6. PLoS One 2012;7:e43768. doi:10.1371/ journal.pone.0043768.

25. Desai VD, Hsia HC, Schwarzbauer JE. Reversible modulation of myofibroblast differentiation in adipose-derived mesenchymal stem cells. PLoS One 2014;9:e86865. doi:10.1371/journal.pone. 0086865.

26. Liu YY, Chiang CH, Hung SC, et al. Hypoxiapreconditioned mesenchymal stem cells ameliorate ischemia/reperfusion-induced lung injury. PLoS One 2017;12:e0187637. doi: 10.1371/ journal.pone.0187637. 
27. Branchett WJ, Lloyd CM. Regulatory cytokine function in the respiratory tract. Mucosal Immunol 2019;12:589-600. doi: 10.1038/s41385-019-0158-0.

28. Pakyari M, Farrokhi A, Maharlooei MK, Ghahary A. Critical role of transforming growth factor beta in different phases of wound healing. Adv Wound Care 2013;2:215-24. doi:10.1089/wound.2012.0406.

29. Mutsaers SE, Prele CMA, Pengelly S, Herrick SE. Mesothelial cells and peritoneal homeostasis. Fertil Steril 2016;106:1018-24. doi: 10.1016/ j.fertnstert.2016.09.005.
30. Schlosser K, Wang JP, Dos Santos C, et al. Effects of mesenchymal stem cell treatment on systemic cytokine levels in a phase 1 dose escalation safety trial of septic shock patients. Crit Care Med 2019;47:918-25. doi:10.1097/CCM.000000000000 3657.

31. Filová E, Brynda E, Riedel T, et al. Improved adhesion and differentiation of endothelial cells on surface-attached fibrin structures containing extracellular matrix proteins. J Biomed Mater Res A 2014;102:698-712. doi:10.1002/jbm.a.34733. 